\title{
MONITORING SISTEM KEAMANAN PINTU MENGGUNAKAN RFID DAN FINGERPRINT BERBASIS WEB DAN DATABASE
}

\author{
Nelly Khairani Daulay ${ }^{1}$, M Nur Alamsyah ${ }^{2}$ \\ ${ }^{1}$ Program Studi Rekayasa Sistem Komputer, Univ. Bina Insan Lubuklinggau \\ ${ }^{2}$ Program Studi Sistem Informasi, Univ. Bina Insan Lubuklinggau \\ e-mail:*11nellydaulay@univbinainsan.ac.id, ${ }^{2}$ mnuralamsyah@univbinainsan.ac.id
}

\begin{abstract}
Abstrak
Kemajuan teknologi memungkinkan setiap penggunaannya dalam aspek kehidupan menjadi lebih mudah, Penggunakan teknologi yang aplikatif salah satunya digunakan dalam keamanan rumah. Dalam penelitian ini, kunci pintu mekanik akan digantikan dengan penggunaan kartu RFID dan pengenalan biometrik, dalam hal ini adalah pengenalan sidik jari. Penggunaan kartu RFID dan sidik jari sebagai pengganti kunci pintu. Kartu RFID dan sidik jari akan dibaca oleh modul mikrokontroler untuk dapat dicocokkan dengan database. Data-data absensi akan dikirimkan ke webserver untuk dapat diakses dimana saja. Untuk menggerakkan pintu digunakan solenoid doorlock Jika sidik jari dan kartu yang dicocokkan tidak sesuai dengan data yang sudah tersimpan dalam program maka akan muncul tampilan sidik jari atau kartu anda salah. Jika sidik jari dan kartu sesuai dengan data yang sudah tersimpan dalam program maka pintu akan membuka.
\end{abstract}

Kata kunci-RFID, fingerprint, Pintu, Monitoring

\begin{abstract}
Advances in technology allow each of its uses in aspects of life to be easier, one of which is the application of applicable technology used in home security. In this study, mechanical door locks will be replaced by the use of RFID cards and biometric recognition, in this case fingerprint recognition. Use of RFID cards and fingerprints instead of door locks. RFID cards and fingerprints will be read by the microcontroller module to be matched to the database. Attendance data will be sent to the webserver to be accessed anywhere. To move the door, a solenoid doorlock is used. If the fingerprint and the card that is matched do not match the data already stored in the program, the fingerprint display or your card will appear incorrectly. If the fingerprint and card match the data already stored in the program, the door will open.
\end{abstract}

Keywords - RFID, fingerprint, Door, Monitoring 


\section{PENDAHULUAN}

Sistem keamanan yang handal menjadi sebuah keharusan untuk mengamankan barang atau benda yang berharga, salah satunya dengan membangun system keamanan dengan menggunakan RFID dan Fingerprint sensor sebagai media autentifikasinya sehingga pengguna atau orang yang akan mengakses ke dalam ruangan tersebut menjadi lebih terseleksi karena orang - orang yang memiliki akses atau orang yang ID dan sidik jarinya terdaftar yang dapat mengakses ruangan tersebut. Sistem perangkat autentifikasi pengamanan pintu menggunakan fingerprint dan RFID dengan Website dan Database sebagai media monitoring dan penyimpanan data pengguna menjadi salah satu solusi dalam membangun sistem keamanan dengan sistem atuentifikasi yang handal karena seluruh identitas pengguna atau karyawan yang mengakses ruangan terekam di dalam database sehingga apabila terjadi masalah pengelola hanya tinggal melihat histori terakhir kali pengguna yang mengakses ruangan tersebut. Ruang Server di STMIK Musirawas Lubuklinggau membutuhkan sistem autentifikasi keamanan pintu yang dapat menyimpan data pengguna dan menyimpan data histori waktu ketika pengguna mengakses pintu tersebut sehingga dapat menunjukkan kapan pintu di akses dengan mengakses website yang dibuat dimana web tersebut sudah terintegrasi dengan sistem ini. Untuk menghindari kegagalan sistem karena sumber listirik yang terputus maka sistem ini juga meggunakan energi listrik cadangan menggunakan Baterai yang berguna menyuplai daya cadangan ketika listrik terputus dari PLN.

Beberapa penelitian yang berkaitan dengan sistem keamanan pintu otomatis yang sudah dlakukan menggunakan berbagai perangkat dan sistem biometrik yang lain. Penelitian yang dilakukan berikut membahas tentang keamanan pintu rumah dengan pengenalan wajah. Sistem ini menggunakan metode eigenface untuk mengenali pola wajah dan modul raspberry Pi sebagai perangkat prosesnya [1][7]. Penerapan sistem keamanan pintu juga diterapkan dalam sistem parkir dengan memanfaatkan fingerprint sebagai biometrik otentification-nya dan kartu RFID [2]. Pengenalan biometrik dengan menggunakan sidik jari dengan penerapannya pada pintu pengaman juga dilakukan menggunakan perangkat proses modul arduino uno [3]. Masih dengan bahasan yang sama, pengenalan biometrik sidik jari menjadi sangat populer dalam penerapannya pada sistem pengaman pintu rumah, sistem yang dirancang juga menggunakan moful mikrokontroler arduino uno sebagai unit prosesnya [4][8][9]. Begitupun sistem smart door lock dapat diterapkan dengan menggunakan fingerprint sebagai alat autentifikasi dengan menggunakan mikrokontroler berbasis arduino pada ruangan [5].

Adapun penerapan RFID dalam hal identifikasi pengguna antara lain diterapkan dalam sistem presensi perkuliahan sehingga menghindari penggunaan absensi secara manual [6]. Aplikasi penerapan sistem keamanan pintu juga dapat diterapkan dengan menggunakan garis telapak tangan menggunakan web cam [10].

Atas dasar beberapa penelitian yang sudah dilakukan diatas, penulis melakukan penelitian berkaitan dengan keamanan rumah berdasarkan penggunaan kartu RFID dan recognisi sidik jari.

\section{TINJAUAN PUSTAKA}

\subsection{Mikrokontroler}

Mikrokontroler ATmega 328P, Mikrokontroler atau sering dinamakan pengontrolan tertanam (Embedded Controler) adalah suatu system yang mengandung masukan/keluaran, memori, 
dan Prosessor yang digunakan pada produk elektronik seperti Pemutar Video pada mobil, Telepon dan Mesin Cuci. Pada Prinsipnya Mikrokontroler adalan sebuah komputer berukuran kecil yan dapat di gunakan untuk mengambil keputusan melakukan hal-hal yang bersifat berulang dan dapat berinteraksi dengan perangkatperangkat eksternal, seperti sensor ultrasonik untuk mengukur jarak terhadap suatu objek, penerima GPS untuk memperoleh data posisi kebumian dari satelit dan motor untuk mengontrol gerakan Robot [11].

\subsection{Sistem Biometrik}

Sebuah sistem biometrik pada dasarnya adalah sebuah sistem pengenalan pola untuk menentukan atau memverifikasi seseorang berdasarkan pada fitur yang berasal dari karakteristik fisiologis atau perilaku tertentu yang dimiliki seseorang [12]. Karakteristik fisiologis atau perilaku yang khas, menyediakan pengukuran dasar biometrik. Biometrik fisiologis didasarkan pada pengukuran langsung dari bagian tubuh manusia, seperti sidik jari (fingerprint), pengenalan iris (iris recognition), pengenalan retina dan pengenalan wajah (face recognition). Sedangkan biometrik perilaku (behaviour) didasarkan pada pengukuran dan data yang berasal dari tindakan, karena itu secara tidak langsung mengukur karakteristik tubuh manusia, seperti tanda tangan, suara, dan ketikan di komputer. Dalam biometrik perilaku biasanya memerlukan waktu yang lebih lama untuk verifikasi dibandingkan biometrik fisiologis.

\subsection{Sidik Jari}

Sebuah sidik jari adalah pola seperti ridge (gundukan) dan alur-alur yang terletak di ujung setiap jari. Sidik jari telah digunakan untuk identifikasi pribadi selama berabad-abad dengan akurasi kecocokan sangat tinggi [13]. Sidik jari terdiri dari pola gunung interleaved (bagian yang naik ke atas) dan sebuah lembah (dips). Langkah pertama dalam pengenalan sidik jari biasanya melibatkan pengkategorian sidik jari menjadi satu dari lima kelas dasar, yang disebut kelas Henry terdiri dari Plain Arch, Tented Arch, Left Loop, Right Loop, dan Whorl (Whorl terbagi menjadi dua lingkaran) polos dan kembar) [14].

\subsection{RFID}

RFID adalah kependekan dari radio frequency identification yang merupakan pengembangan teknologi komunikasi wireless yang digunakan secara unik untuk mengidentifikasi benda atau orang yang ditag. RFID mengunakan teknologi yang memanfaatkan frekuensi radio untuk identifikasi otomatis terhadap suatu objek [15]. RFID mampu memberikan tingkat integritas data yang tinggi walaupun RFID bekerja pada lingkungan yang ekstrim sekalipun serta mampu memberikan tingkat keamanan yang tinggi, karena teknologi ini sulit untuk dipalsukan [16].

\section{METODOLOGI PENELITIAN}

\subsection{Perancangan Sistem}

\subsubsection{Spesifikasi Alat}

- Mikrokontroler Atmega328P

- RFID Card;

- Fingerprint Modul;

- Ethernet Shield;

- Note Book (PC);

\subsubsection{Rancangan Input Sistem}

Perancangan input sistem terdiri dari dua bagian, yaitu Input Sensor Sidik Jari dan Input RFID Modul. Gambar 1 berikut menyajikan rangkaian sistem sidik jari yang terhubung dengan modul arduino. Gambar 2 menyajikan rangkaian sistem RFID yang terhubung dengan arduino. 


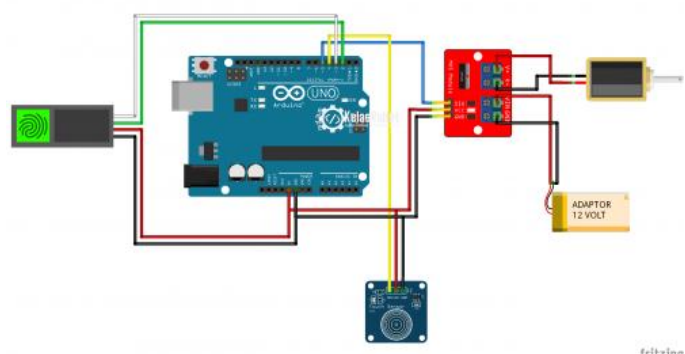

Gambar 1. Rangkaian Input Fingerprint

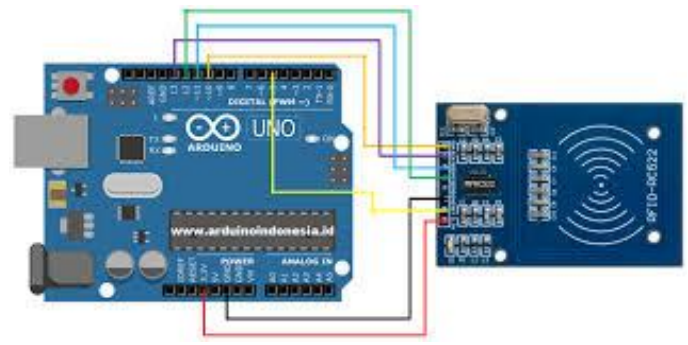

Gambar 2. Rangkaian Input RFID

\subsubsection{Rancangan Output Sistem}

Rancangan output sistem terdiri dari solenoid door lock dan output ethernet shield sebagai media transfer datanya. Gambar 4 menyajikan Rangkaian solenoid door lock yang terhubung ke arduino.

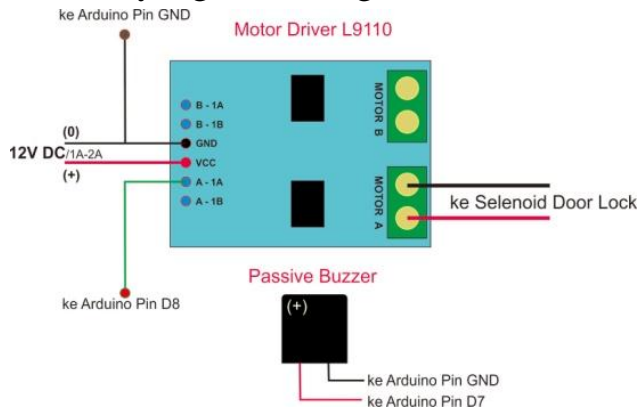

Gambar 3. Rangkaian Output Solenoid

\subsection{Desain Sistem}

Setelah mendapatkan inti dari permasalahan peneliti membuat desain system berupa blok diagram dari Sistem Keamanan Pintu Menggunakan RFID Dan Fingerprint Berbasis Web dan Database Sebagai Media Monitoring Dan Media Penyimpanan Data Pengguna.

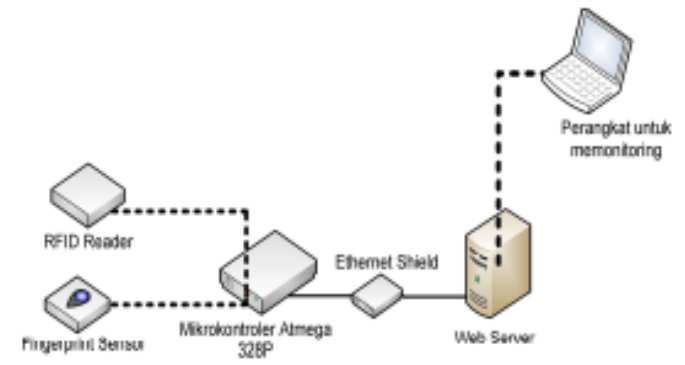

Gambar 4. Desain Sistem Keamanan Pintu menggunakan Fingerprint dan RFID

Pengalamatan IP pada system ini menggunakan IP statis Lokal karena data akan di simpan menggunakan server lokal dan hanya dapat diakses dari dalam Jaringan yang ada di STMIK Musirawas.

Tabel 1. Pengalamatan IP

\begin{tabular}{|c|c|c|c|}
\hline No & $\begin{array}{c}\text { Nama } \\
\text { Perangkat }\end{array}$ & IP Address & Ket \\
\hline 1 & $\begin{array}{l}\text { Ethernet } \\
\text { Shield }\end{array}$ & 100.100 .100 .115 & $\begin{array}{l}\text { IP yang } \\
\text { ada di } \\
\text { sistem } \\
\text { keamanan }\end{array}$ \\
\hline 2 & $\begin{array}{l}\text { Web } \\
\text { Server }\end{array}$ & 100.100 .100 .200 & $\begin{array}{l}\text { IP Address } \\
\text { yang } \\
\text { terhubung } \\
\text { ke } \\
\text { perangkat } \\
\text { sistem } \\
\text { keamanan }\end{array}$ \\
\hline
\end{tabular}

\subsection{Alur Kerja Sistem}

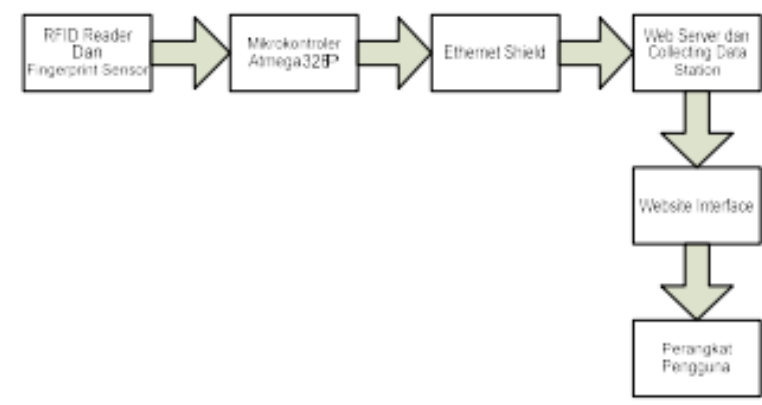

Gambar 5. Alur Kerja Sistem

Ketika kartu RFID didekatkan ke pembaca RFID makan akan menghidupkan Arduino (ATMega 328P) dan Fingerprint kemudian fingerprint akan membaca sidik jari yang di tempelkan ke sensor kemudian 
Arduino akan memproses data sidik jari tersebut apakah terdaftar di dalam sistem atau tidak jika terdaftar maka arduino melalui Ethernet shield akan mengirimkan data pengguna ke dalam database untuk disimpan data waktu serta siapa yang membuka pintu.

\section{HASIL DAN PEMBAHASAN}

\subsection{Hasil Perancangan}

Setelah melakukan analisis kebutuhan komponen dan perangkat pendukung untuk membuat sistem keamanan pintu otomatis kemudian dilakukan pembuatan sistem dan hasil dari perangkat keras dan perangkat lunak. Gambar 6 menunjukkan perangkat keras sistem secara keseluruhan.

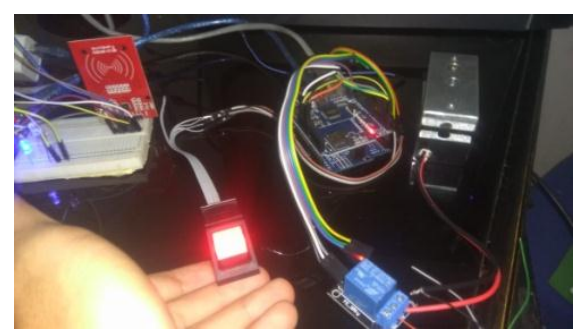

Gambar 6. Hasil Rancangan Perangkat Keras

Sebagai output dari sistem peneliti menggunakan interface web untuk menampilkan data pengguna. Gambar 7 menampilkan halaman login dari sistem keamanan pintu ruang servar yang dirancang.

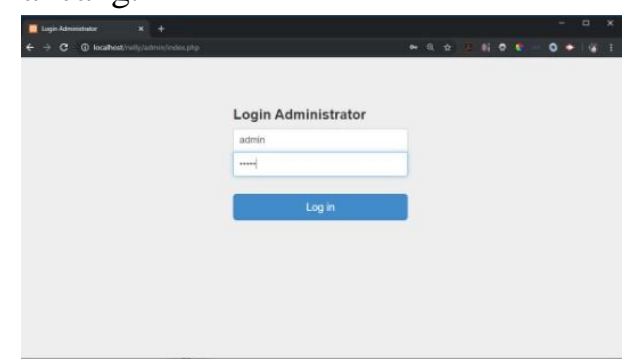

Gambar 7. Hasil Rancangan Halaman Login

Setelah pengguna login, maka seperti pada gambar 8 akan masuk ke dalam menu aplikasi sistem.

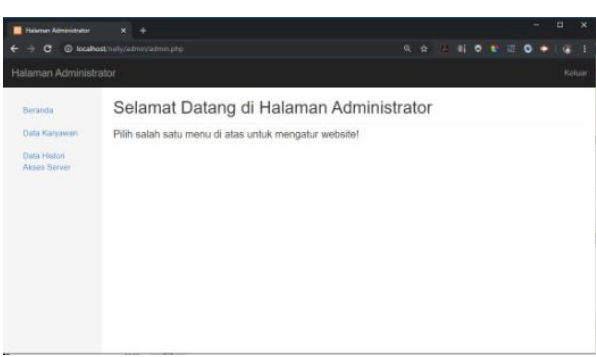

Gambar 8. Tampilan Hasil Menu

Pada halaman menu, terdapat menu karyawan yang merupakan data akses terhadap pintu masuk server. Gambar 9 berikut menyajikan data karyawan pada sistem.

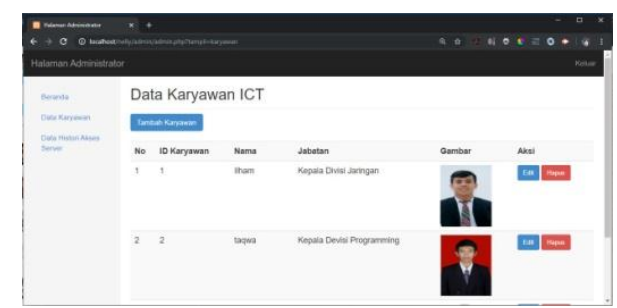

Gambar 9. Tampilan Hasil Menu Data Karyawan

Pada sistem ini juga terdapat data historis akses ke ruangan server, sehingga dapat dipantau siapa saja yang telah masuk ke ruangan tersebut. Gambar 10 menyajikan data historis penggunaan akses ruangan.

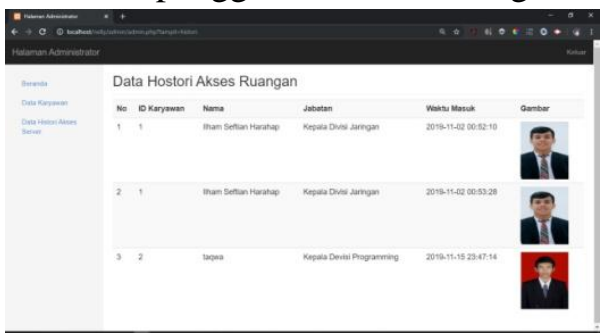

Gambar 10. Tampilan Hasil Menu Historis akses Ruangan

\subsection{Pengujian Sistem}

Pengujian dilakukan untuk mengetahui sejauh mana sistem dapat bekerja dengan baik.

\subsubsection{Pengujian Catu Daya}

Pengujian catu daya dilakukan apakah catu daya yang dipakai berfungsi sesuai dengan yang diharapkan. Tabel 2 menyajikan hasil pengukuran catu daya. 
Tabel 2. Hasil Pengujian Catu Daya

\begin{tabular}{|c|c|}
\hline $\begin{array}{l}\text { Hasil } \\
\text { Ukur }\end{array}$ & Ket \\
\hline $12 \mathrm{Vac}$ & Input $12 \mathrm{~V}$ Trafo \\
\hline $16 \mathrm{Vdc}$ & $\begin{array}{c}\text { Output Dioda Brigde } \\
\text { Output Regulator }\end{array}$ \\
\hline $12 \mathrm{Vdc}$ & $\begin{array}{c}7812 \\
\text { Output Regulator }\end{array}$ \\
\hline $5 \mathrm{Vdc}$ & 7805 \\
\hline
\end{tabular}

\subsubsection{Pengujian Waktu Fingerprint}

Implementasi dari fingerprint sensor ini dapat bekerja dengan baik, hal tersebut dapat dilihat dari sensor yang dapat mengenali sidik jari seseorang yang sudah dilakukan perekaman data pada sebelumnya. Pengujian fingerprint dilakukan dengan mengukur lama baca data sidik jari. Pengujian fingerprint sensor dapat dilihat pada tabel 3 berikut.

Tabel 3. Pengujian Waktu Pembacaan Fingerprint.

\begin{tabular}{cc}
\hline No. ID & Rata-Rata Waktu Baca (s) \\
\hline$\# 1$ & 1,95 \\
$\# 2$ & 2,04 \\
$\# 3$ & 2,13 \\
$\# 4$ & 2,23 \\
\hline
\end{tabular}

Dari data percobaan dapat dinyatakan bahwa fingerprint sensor dapat mengenali sidik jari yang sebelumnya telah direkam.

\subsubsection{Pengujian RFID Reader}

Pengujian reader dilakukan dengan mengukur jarak baca dan mengukur lama baca data. Pengujian dari jarak reader membaca tag dapat dilihat pada tabel 4 .

Tabel 4. Jarak baca reader

\begin{tabular}{cc}
\hline No. ID & Jarak Baca $(\mathbf{c m})$ \\
\hline$\# 1$ & $0-2,5$ \\
$\# 2$ & $0-2,5$ \\
$\# 3$ & $0-2,5$ \\
$\# 4$ & $0-2,5$ \\
\hline
\end{tabular}

Kemudian untuk pengujian waktu reader membaca RFID tag dapat dilihat pada tabel 5.

Tabel 5. Waktu baca RFID reader

\begin{tabular}{cc}
\hline No. ID & Rata-Rata Waktu Baca $(\mathbf{S})$ \\
\hline$\# 1$ & 0,68 \\
$\# 2$ & 0,70 \\
$\# 3$ & 0,71 \\
$\# 4$ & 0,69 \\
\hline
\end{tabular}

Dari tabel 4 dan 5 dapat dinyatakan bahwa reader dapat membaca RFID tag dengan baik. Kemampuan jarak baca reader juga cukup baik, karena RFID tag yang digunakan pasif, sehingga jarak $2,5 \mathrm{~cm}$ sudah cukup baik untuk reader dalam membaca RFID tag.

\subsection{Pembahasan}

Ada dua perangkat lunak yang membantu sistem ini, yaitu program database yang digunakan untuk memasukkan entri pengguna dan program user interface pada web server untuk menampilkan log dari sistem.

Program Database :

Program database menggunakan MySQL. Function dari database dapat dipanggil untuk membantu program utama dan program yang lain.

User Interface :

Digunakan untuk menampilkan tampilan pengguna untuk memonitoring hasil penggunaan sistem.

\section{KESIMPULAN}

Dari hasil pengujian diatas, maka dapat disimpulkan bahwa RFID reader dan sensor sidik jari dapat membaca pengenalan pengguna dengan keberhasilan yang sangat baik. Kartu RFID dapat membaca dengan baik pada jarak $2,5 \mathrm{~cm}$ dengan rata-rata pembacaan pada setiap user selama 0,7 detik. Untuk pengujian fingerprint juga sangat baik, dengan rata-rata waktu pembacaan selama 2,2 detik. 
VI. SARAN

Penelitian ini masih mengalami kekurangan, untuk penelitian kedepan disarankan untuk memberikan sub sistem agar dapat menutup pintu.

\section{DAFTAR PUSTAKA}

[1] Kurniawan, R. and Zulius, A., 2019. Smart Home Security Menggunakan Face Recognition Dengan Metode Eigenface Berbasis Raspberry Pi. Jurnal Sustainable: Jurnal Hasil Penelitian dan Industri Terapan, 8(2), pp.48-56..

[2] Utomo, M.R., Karna, N. and Mayasari, R., 2019. Perancangan Dan Implementasi Sistem Keamanan Parkir Dengan Fingerprint Pada Parkiran Telkom University. eProceedings of Engineering, 6(1)..

[3] Yalandra, H. and Jaya, P., 2019. Rancang Bangun Pengaman Pintu Personal Room Menggunakan Sensor Sidik Jari Berbasis Arduino. Jurnal Vokasional Teknik Elektronika dan Informatika, 7(2), pp.118-125.

[4] Siswanto, A., Yulianti, A. and Costaner, L., 2018. Sistem Pengaman Pintu Rumah Dengan Teknologi Biometrik Sidik Jari Berbasis Arduino. Jurnal Penelitian Pos dan Informatika, 8(2), pp.97-107.

[5] Padeli, P., Febriyanto, E. and Suprayogi, D., 2019. Prototype Sistem Smart Lock Door Dengan Timer Dan Fingerprint Sebagai Alat Autentikasi Berbasis Arduino Uno Pada Ruangan. Journal of Innovation and Future Technology (IFTECH), 1(1), pp.51-59.

[6] Natalianto, N., 2018. Sistem Presensi Perkuliahan Berbasis Radio Frequency Identification. Media Teknika, 12(2).

[7] Ridho, A., Ariyanto, E. and Jadied,
E., 2017. Implementasi Kunci

Otomatis Menggunakan Face Recognition Dan Pintu Otomatis Menggunakan Speech Recognition Berbasis Raspberry Pi. eProceedings of Engineering, 4(3).

[8] Siswanto, A., Yulianti, A. and Costaner, L., 2017. Arsitektur Sistem Keamanan Rumah Dengan Menggunakan Teknologi Biometrik Sidik Jari Berbasis Arduino. In Seminar Nasional Aptikom 2017 (pp. 323-327).

[9] Prakasa, G.A., Aris Rakhmadi, S.T. and Eng, M., 2017. Prototype Sistem Kunci Pintu Berbasis Qrcode Dan Arduino., Universitas Muhammadiyah Surakarta.

[10] Rafika, M., Rakhman, A. and Endri, J., 2017. Rancang dan Implementasi Pattern Recognition pada Garis Telapak Tangan untuk Akses Keamanan Pintu. Prosiding SNATIF, pp.413-418.

[11] Kadir Abdul, 2015, Buku Pintar Pemrograman Arduino, Mediakom, Yokyakarta.

[12] Prabhakar, S., Pankanti, S., \& Jain, A. K.,. 2003.. Biometric recognition: Security and privacy concerns. IEEE security \& privacy, 99(2), 33-42.

[13] Maio, D., Maltoni, D., Cappelli, R., Wayman, J. L., \& Jain, A. K. 2002. FVC2000: Fingerprint verification competition. IEEE transactions on pattern analysis and machine intelligence, 24(3), 402-412.

[14] Maltoni, D., Maio, D., Jain, A. K., \& Prabhakar, S. 2009. Securing Fingerprint Systems. Handbook of Fingerprint Recognition, 371-416.

[15] Ardaninggar, E. A., 2016, Sistem Keamanan Portal Perumahan Berbasis RFID, Tugas Akhir, Jurusan Teknik Elektro, FST, 
Universitas Sanata Dharma,

Yogyakarta.

[16] Harsono, B., Liman, J., dan Djohan, N., 2012, Aplikasi RFID Sebagai

Pengaman Pintu Masuk, vol.01, no.01, Jan-Maret 2012, hal 2-6. 